\title{
Cone reconstruction for Ebstein's anomaly: Patient outcomes, biventricular function, and cardiopulmonary exercise capacity
}

\author{
Michael Ibrahim, MD, PhD, ${ }^{\text {a,b }}$ Victor T. Tsang, MD, FRCS, ${ }^{\text {a,b,c }}$ Maryanne Caruana, MD, ${ }^{\mathrm{d}}$ \\ Marina L. Hughes, DPhil, FRACP, ${ }^{\mathrm{d}, \mathrm{e}}$ Synetta Jenkyns, BD, ${ }^{\mathrm{e}}$ Elodie Perdreau, MD, \\ Alessandro Giardini, MD, ${ }^{\mathrm{c}, \mathrm{e}}$ and Jan Marek, MD, $\mathrm{PhD}^{\mathrm{c}, \mathrm{e}}$
}

\begin{abstract}
Objective: Cone reconstruction is advocated to treat severe tricuspid valve (TV) regurgitation associated with Ebstein's anomaly. Data on postoperative clinical status, ventricular adaptation, and objective cardiopulmonary testing are lacking in these patients.
\end{abstract} Methods: The clinical characteristics, echocardiography, magnetic resonance imaging, and exercise data from
27 consecutive cone reconstructions, undertaken from 2009 to 2013, were retrospectively compared between
preoperative baseline and follow-up.

\begin{abstract}
Results: There were no deaths. The cone TV functioned well in all but 1 patient with late dehiscence of inferior annuloplasty sutures that were subsequently repaired. Four patients required pacemaker insertion ( 3 for new complete heart block). At median follow-up of $2.7 \pm 1.5$ years, tricuspid regurgitation was reduced in all patients, without causing stenosis. Global left ventricle function remained unchanged (pre-operative fraction $60 \% \pm$ $4 \%$ vs postoperative fraction $61 \% \pm 3 \% ; P=.96$ ). MRI showed enhanced forward pulmonary flow (pre $26 \pm$ $1 \mathrm{~mL} /$ beat vs post $36 \pm 10 \mathrm{~mL} /$ beat; $P<.005$ ) and increased left ventricle filling (body surface area-indexed left ventricle end-diastolic volume pre $49 \pm 14 \mathrm{~mL} / \mathrm{m}^{2}$ vs post $60 \pm 14 \mathrm{~mL} / \mathrm{m}^{2} ; P<.005$ ). New York Heart Association functional class improved (pre $2.5 \pm 0.6$ vs post $1.3 \pm 0.6 ; P<.0001$ ) and there was significant improvement in peak oxygen uptake (pre $54 \% \pm 18 \%$ vs post $66 \% \pm 22 \% ; P=.02$ ).
\end{abstract}

Conclusions: Cone reconstruction of TV offers an effective repair in patients with severe regurgitation associated with Ebstein's anomaly. The patients' clinical status improved with better left ventricle filling and objective exercise capacity. The durability of repair, and mechanisms by which the ventricles adapt to the new loading conditions, need longer-term study. (J Thorac Cardiovasc Surg 2015;149:1144-50)

See related commentary on pages $1150-1$.

Ebstein's anomaly (EA) is a rare cardiac defect accounting for approximately $1 \%$ of all congenital cardiac abnormalities. It is characterized by apical displacement of the septal and inferior leaflets of the tricuspid valve (TV) and consequent atrialization of a portion of the RV. ${ }^{1}$ EA may present at any age, with a natural history related to the severity of the lesion. ${ }^{2}$

A number of surgical approaches to repair EA have been described..$^{3-5}$ In 2007 da Silva and colleagues ${ }^{6}$ described the

\footnotetext{
From the Departments of Cardiothoracic Surgery ${ }^{\mathrm{a}}$ and Cardiology, ${ }^{\mathrm{e}}$ Great Ormond Street Hospital for Children, London, United Kingdom; Departments of Cardiothoracic Surgery ${ }^{\mathrm{b}}$ and Cardiology, ${ }^{\mathrm{d}}$ Heart Hospital, London, United Kingdom; and Institute of Cardiovascular Sciences, ${ }^{\mathrm{c}}$ University College London, United Kingdom.

Disclosures: Authors have nothing to disclose with regard to commercial support. Received for publication May 22, 2014; revisions received Dec 17, 2014; accepted for publication Dec 25, 2014; available ahead of print Feb 19, 2015.

Address for reprints: Victor T. Tsang, MD, FRCS, Department of Cardiothoracic Surgery, Great Ormond Street Hospital, Level 7, Old Nurses Home, Great Ormond St, London WC1N 3JH, United Kingdom (E-mail: Victor.tsang@gosh.nhs.uk). 0022-5223/\$36.00

Copyright $($ c 2015 by The American Association for Thoracic Surgery http://dx.doi.org/10.1016/j.jtcvs.2014.12.074
}

cone reconstruction technique that involves delamination and rotation of the detached TV anterosuperior leaflet and the use of the remnant of the septal and inferior leaflets to create a cone, the vertex of which faces the RV apex. With sufficient valve tissue, this technique promotes the full coaptation of valve leaflets, with a more physiologic distribution of stresses and the creation of a central bloodstream through the new TV. This recently introduced method consistently improves the functional anatomy of RV inflow and provides a hospital mortality of $2.5 \%$ with a reduction in tricuspid regurgitation (TR) grade from $3.6 \pm 0.5$ preoperatively to $1.2 \pm 0.4$ postoperatively. ${ }^{6}$ These early encouraging results have also been supported by the surgical series from Boston and the Mayo clinic. ${ }^{7-9}$

Despite the good early outcomes, data on postoperative $\mathrm{RV}$ and left ventricle (LV) adaptation, and objective cardiopulmonary testing are lacking.

The aims of our study were to describe our results and determine the integrity of the cone reconstruction in patients with symptomatic EA with significant TR, to use echocardiographic and magnetic resonance imaging (MRI) data to compare preoperative and postoperative biventricular size and function, and to objectively compare exercise capacity before and after surgery. 


\section{Abbreviations and Acronyms \\ $\mathrm{CMR}=$ cardiac magnetic resonance \\ EA $=$ Ebstein's anomaly \\ $\mathrm{LV}=$ left ventricle \\ MRI = magnetic resonance imaging \\ $\mathrm{RV}=$ right ventricle \\ $\mathrm{TR}=$ tricuspid regurgitation \\ $\mathrm{TV}=$ tricuspid valve}

\section{METHODS}

\section{Study Design}

This was a retrospective observational study using systematically acquired pre- and postoperative data from study participants in the shortto mid-term. Ethical approval for data collection was granted following local ethical review.

\section{Patient Selection}

Beginning in 2009, all symptomatic EA patients with moderate or severe TR who were considered for surgery were referred for cross-sectional imaging, involving echocardiography and cardiac magnetic resonance, unless contraindicated. Cardiopulmonary exercise testing was included in the preoperative assessment.

Those considered to have suitable TV anatomy (sufficiently mobile and abundant anterosuperior leaflet for the creation of a cone valve) were offered the cone reconstruction. All patients who underwent a cone reconstruction are included in the analysis (Table 1).

\section{Surgical Procedure}

All operations were performed by a single surgeon (V.T.T.) at 2 centers, in which all patients were followed-up.

The procedures were performed under mild hypothermic $\left(34^{\circ} \mathrm{C}\right)$ cardiopulmonary bypass with intermittent antegrade cold blood cardioplegia. The cone reconstruction has been described previously, ${ }^{6}$ and is challenging surgery in which a number of elements need to be considered, including the heterogeneous TV morphology. Bridging of the often deficient inferior leaflet poses more difficulties than the deviated and deficient septal leaflet.

The anterosuperior leaflet of the TV is detached from the annulus en bloc, and the accessory attachments of the leaflets to the ventricular walls are divided, providing access to the subvalvular apparatus. It is essential to delaminate the deficient septal and inferior leaflets, if present. The free edge of the reconstructed inferior leaflet is rotated clockwise and sutured to the reconstructed septal leaflet edge, forming a new TV surrounded by native leaflet tissue with an apical papillary attachment.

In some cases the inflow orifice toward the infundibulum and any commissural deficiency or leaflet fenestrations may require closure to improve the competency of the reconstructed valve. In valves with extensive muscularization of the leaflets, surgically created fenestrations may be required to offer unrestrictive inflow. If present, an enlarged atrialized RV chamber is reduced using endocardial, longitudinal plicating sutures, without compromising the epicardial branches of the right coronary artery.

The neoannulus is reconstructed by plication of the dilated TV annulus (anteroseptal and inferioseptal annuloplasty) onto which the newly reconstructed cone valve is reattached, nearly restoring its anatomical position. The restored leaflet coaptation is confirmed at surgery by filling the RV with saline through a bulb syringe and by visually inspecting the leaflets. In addition, after weaning from cardiopulmonary bypass, intraoperative transoesophageal echocardiography is used to assess the results of the valve reconstruction. A small atrial communication is often left in situ to assist the early postoperative management of RV functional impairment. Concomitant maze procedure was used for patients with symptomatic preoperative arrhythmias refractory to electrophysiologic ablation.

The postoperative management is focused around the support of RV function with vasodilators and agents to maintain low pulmonary vascular resistance. There is a low threshold to administer prophylactic amiodarone for the management of atrial tachyarrhythmia.

\section{Transthoracic Echocardiography}

Transthoracic conventional echocardiographic studies were performed using Vivid 7, Vivid e9 machines (GE, Milwaukee, Wis). ${ }^{10}$ Subcostal, apical 4-chamber and parasternal long- and short-axis views were used to obtain images on the morphology of tricuspid valve, atrial and ventricular chambers, and right ventricular outflow tract. All echocardiographic recordings were stored on digital versatile discs for offline analyses with Echopac software (GE). All measurements were supervised by J.M. Measurements were made over 3 cardiac cycles, and the average was used for statistical analysis. Whereas echocardiography was performed on all patients pre- and postoperatively, formal quantitative assessment was available for 24 patients. Data from the latest available echocardiogram was used in this study. Postoperative echocardiographic studies were completed within 6 months.

\section{Cardiac Magnetic Resonance (CMR)}

CMR imaging was performed on a $1.5 \mathrm{~T}$ scanner (Avanto, Siemens Medical Solutions, Erlangen, Germany). Evaluation of ventricular and valve function was achieved using retrospectively gated, breath-held, balanced, steady-state free-precession cine images. The TV leaflet attachments and the margins of right atrium and right ventricle were visualized and analyzed throughout the cardiac cycle in multiple planes. Net flow through the pulmonary valve and aortic valve was measured using electrocardiogram-triggered, breath-hold cine phase contrast flow mapping. Flow image planes were planned perpendicular to the proximal main pulmonary artery and perpendicular to the ascending aorta.

During postprocessing, ventricular volumes were measured by manually tracing the blood-endocardium boundary for each slice at end-diastole and end-systole. The ventricular volume was then determined by summation of the volumes of all slices. From these data ventricular stroke volumes and ejection fraction were calculated. TV regurgitant fraction was calculated by subtracting the pulmonary forward flow stroke volume from the RV stroke volume, and expressing the remainder as a percentage of the RV stroke volume. CMR was available for analysis in 16 patients preoperatively and 15 patients postoperatively. Postoperative CMR was completed within 6 months of surgery.

\section{Cardiopulmonary Exercise Test}

Due to the young age of some patients, objective exercise testing was not possible in all patients. Pre- and postoperative objective exercise capacity, using cardiopulmonary testing protocols or the Bruce test, is available for 13 patients. Data are presented as absolute peak oxygen uptake and also as a percentage of predicted peak oxygen uptake. Cardiopulmonary exercise testing was performed on a bicycle ergometer with an initial, unloaded warm-up. Following this, the workload was increased by 10 to $20 \mathrm{~W} / \mathrm{min}$. The patients were encouraged to exercise until exhaustion after about 10 minutes of loaded exercise. The tests were considered maximal with a respiratory exchange ratio of $\geq 1.09$. The 12-lead electrocardiogram was monitored continuously and blood pressure was recorded every 2 minutes. Breath-by-breath respiratory gas exchange measurements were recorded throughout the test. The peak oxygen uptake was defined as the average of the values obtained in the last 20 seconds of exercise. 
TABLE 1. Patient characteristics

\begin{tabular}{lc}
\hline \multicolumn{1}{c}{ Characteristic } & Result \\
\hline Patients participating & 27 \\
Age (y) & $15.8(22 \mathrm{~d}-56.9 \mathrm{y})$ \\
Male/female & $13 / 14$ \\
Weight (kg) & $50.1 \pm 25.1$ \\
Body surface area & $1.49 \pm 0.44$ \\
Atrial septal defect/patent foramen ovale & 12 \\
Ventricular septal defect & 1 \\
Pulmonary valve stenosis/regurgitation & 2 \\
Previous bidirectional cavopulmonary shunt & 1 \\
Previous pulmonary valvotomy & 1 \\
Previous atrial septal defect closure device & 1 \\
Previous flutter ablation & 1 \\
Previous mitral valve repair & 1 \\
Cardiopulmonary bypass time & $153.8 \pm 34.0$ \\
Crossclamp time & $93.2 \pm 22.0$ \\
Concomitant maze procedure & 1 \\
Concomitant tricuspid valve annuloplasty & 27 \\
Concomitant other valvular procedure & 1x pulmonary homograft* \\
Concomitant permanent pacemaker & 1 \\
Concomitant right ventricular outflow tract & 1 \\
obstruction relief with patch & \\
Values are presented as n, median (range), or mean \pm standard deviation. *One pa- \\
tient underwent concomitant pulmonary homograft.
\end{tabular}

\section{Statistical Analysis}

Continuous variables are presented as mean \pm standard deviation, and $n$ denotes the number of patients, unless otherwise stated. When comparing 2 groups (pre- and postoperative mean values), a nonparametric $t$ test was performed. Paired $t$ test analyses were performed using Wilcoxon matched-pairs signed rank test.

\section{RESULTS}

\section{Patients and Operative Characteristics}

At the time this study closed, we have had 55 patients referred to us with EA. Of these, 27 underwent cone operation. The other patients fall into the following categories: awaiting full workup and decision $(\mathrm{n}=5)$, care moved to another center for medical follow-up more locally $(\mathrm{n}=8)$, have died $(\mathrm{n}=1$ patient due to cancer), asymptomatic with moderate anomalies and receiving medical follow-up $(n=13)$, and declined operation $(n=1)$.

Twenty-seven symptomatic patients with EA, significant $\mathrm{TR}$, and progressive right heart dilation underwent cone reconstruction between 2009 and 2013 (Table 1). Up-to-date clinical follow-up was available in all patients. There were no early or late deaths during the follow-up period up to 4 years. One patient, an 11-year old male patient, had a redo sternotomy for a reduction of a surgically created atrial septal defect on postoperative day 4, with good recovery. Median follow up was $2.7 \pm 1.5$ years.

\section{Arrhythmias/Heart Block}

Preoperatively, 3 patients had atrial flutter/fibrillation and 1 had intermittent atrioventricular block. Four patients required pacemaker insertion at the time of cone reconstruction (3 for new complete heart block). Early postoperative episodes of atrial arrhythmia were all managed according to current practice without complications. We had a low threshold for amiodarone use in 22 patients for early transient postoperative atrial arrhythmia, used for a maximum of 3 months. There were no episodes of late arrhythmia or heart block.

\section{Tricuspid Cone Valve Integrity}

The valve repair appeared to be robust during the follow-up period, except in 1 patient (a 59-year old man) who had a late reoperation (9 months postrepair) for dehiscence of the inferior annuloplasty sutures. His repair occurred early in our series, and the dehiscence was probably due to the high wall tension in a preexisting markedly dilated RV. Interestingly the newly formed cone TV was intact, and the paravalvular leak was successfully repaired using a triangular bovine pericardial patch without further complications.

\section{Tricuspid Cone Valve Function}

Echocardiographic analysis of the cone valve showed a postoperatively reduced TV annulus size (preoperative $47.5 \pm 13.4 \mathrm{~mm}$ vs postoperative $28.3 \pm 8.3 \mathrm{~mm}$; $P<.0001$ ) and a reduced grading of TR (preoperative 3.6 \pm 0.4 vs postoperative $2.3 \pm 0.8 ; P<.0001)$. TR jet velocity was low in both preoperative (peak oxygen uptake $2.4 \pm 0.6$ $\mathrm{m} / \mathrm{s}$ ) and postoperative periods (peak oxygen uptake $2.4 \pm$ $0.4 \mathrm{~m} / \mathrm{s}$; nonsignificant). TV annulus $z$ score was $13.5 \pm 3.5$ preoperatively versus $0.05 \pm 0.14$ postoperatively $(P<.001)$. There was no evidence of TV stenosis.

\section{Right and Left Heart Structure and Function}

Echocardiographic right atrial area was decreased (preoperative $29 \pm 17 \mathrm{~cm}^{2}$ vs postoperative $18 \pm 9 \mathrm{~cm}^{2}$; $P<.0001)$ resulting in a lower right atrium to left atrium ratio (preoperative $3.4 \pm 1.6$ vs postoperative $1.4 \pm 0.4$; $P<.0001)$. These changes indicate a trend toward normalization of the anatomy of the right heart. RV ejection fraction calculated using CMR did not change following surgery (preoperative $44.5 \% \pm 10.4 \%$ vs postoperative $38.6 \% \pm 10.4 \% ; P=.12$ ). The overall effect on RV performance is complex and requires longitudinal assessment. This is discussed below.

Global LV function measured by biplane Simpson remained unchanged and within normal limits in all patients (preoperative ejection fraction $60 \% \pm 3 \%$ vs postoperative ejection fraction $61 \% \pm 3 \% ; P=.96)$. The systolic LV eccentricity index (preoperative $1.2 \pm 0.4$ vs postoperative $1.0 \pm 0.2$; nonsignificant) and LV shortening function (preoperative $27 \% \pm 13 \%$ vs postoperative $33 \% \pm 8 \%$; nonsignificant) did not change significantly following surgery. However, CMR analysis showed that the cone reconstruction enhanced filling of the LV. The increase in 
TABLE 2. Cardiac magnetic resonance imaging analysis of effect of cone reconstruction on right ventricle $(\mathrm{RV})$ and left ventricle (LV) volumes

\begin{tabular}{lccc}
\hline & Preoperative & Postoperative & $\boldsymbol{P}$ value \\
\hline RV end-systolic volume & $112.1 \pm 80.6$ & $91.0 \pm 45.3$ & .54 \\
RV end-diastolic volume & $166 \pm 66.3$ & $145.9 \pm 56.1$ & .24 \\
LV end-systolic volume & $19.8 \pm 8.9$ & $22.4 \pm 10.4$ & .25 \\
LV end-diastolic volume & $49.4 \pm 14.4$ & $60.14 \pm 14.5$ & $\mathbf{. 0 0 6}$ \\
\hline
\end{tabular}

All values are indexed for body surface area. Boldface type indicates statistical significance. $R V$, Right ventricle; $L V$, left ventricle.

postoperative (body surface area-indexed) LV end-diastolic volumes (preoperative $49 \pm 14 \mathrm{~mL} / \mathrm{m}^{2}$ vs postoperative 60 $\pm 14 \mathrm{~mL} / \mathrm{m}^{2} ; P<.005$ ) (Table 2 ) suggested a sustained ability of the heart to drive forward blood flow following a large reduction in TR. This was investigated further by analysis of the forward flow in the main pulmonary artery, which was significantly enhanced following surgery (preoperative $25 \pm 1 \mathrm{~mL} /$ beat vs postoperative $36 \pm 10 \mathrm{~mL} / \mathrm{beat}$; $P<.005$ ) (Figure 1).

\section{Clinical Status and Exercise Capacity}

All patients were symptomatic preoperatively. The cone reconstruction improved postoperative functional status, in terms of New York Heart Association functional class, in all patients (preoperative $2.5 \pm 0.6$ vs postoperative 1.3 $\pm 0.6 ; P<.0001$ ) (Figure 2). Figure 3 shows that peak oxygen uptake increased significantly following surgery (peak oxygen uptake preoperatively $21 \pm 6$ vs postoperatively $25 \pm 9 ; P=.03$ ). Due to the wide age range, of more significance is the objective exercise capacity relative to percentage predicted, which also showed a significant improvement following surgery (percent predicted peak oxygen uptake preoperatively $53 \pm 17$ vs postoperatively $66 \pm 22 ; P=.02$ ). Pre- and postoperative oxygen saturations did not change significantly (preoperative $87.4 \% \pm 9.5 \%$ vs postoperative $93.6 \% \pm 4.7 \% ; P=.07)$.

\section{DISCUSSION}

Cone reconstruction is safe and effective at reducing TR. In the midterm, TV function is maintained, and LV filling is enhanced, with associated improvements in New York Heart Association functional class and objective exercise capacity. In our selected cohort of patients, age at surgery, valve morphology, degree of cyanosis, presence of atrial septal defect, and functional RV size, had no substantial effects on surgical outcomes. There was no major cardiovascular event at follow-up, except 1 patient with a paravalvular leak due to dehiscence of the inferior annuloplasty sutures.

\section{Surgery}

Recent observations $^{2,3}$ that TR in EA can progress with negative attrition and that occurrence of significant TR has an adverse effect on exercise tolerance, arrhythmias,

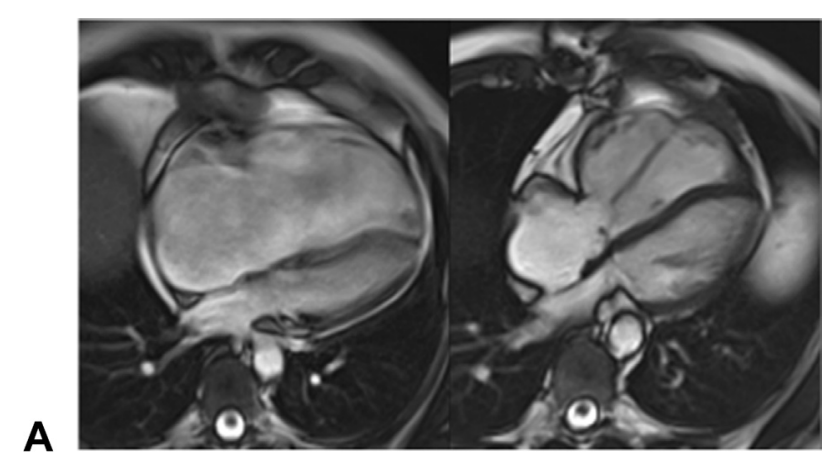

Indexed Forward Flow in MPA

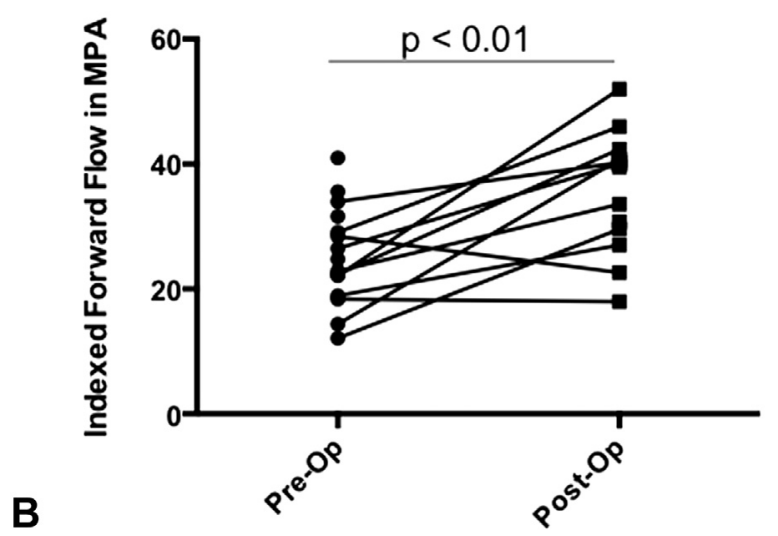

FIGURE 1. Effect of cone reconstruction on right ventricle forward flow, measured with cardiac magnetic resonance (CMR) imaging. A, Pre- and postoperative CMR images of Ebstein's anomaly, showing that the cone operation reduces right atrium size and enhances left ventricle size. $\mathrm{B}$, The right ventricle achieves improved forward flow volume into the main pulmonary artery (MPA), as measured by CMR imaging phase-contrast flow mapping. preop, Preoperative; postop, postoperative.

and congestive heart failure have generally encouraged surgeons to offer repair when severe TR and right heart dilation are present. Many approaches to the surgical repair of EA have been forwarded. The approach offered by Danielson and Fuster ${ }^{3}$ is to repair the displaced TV using a transverse plication of the atrialized chamber. Carpentier et $\mathrm{al}^{4}$ described the detachment and mobilization of the anterior leaflet to achieve maximum mobility followed by longitudinal plication of the atrialized RV and the adjacent RA. The TV was then reattached at its anatomic level, usually with a prosthetic annuloplasty ring. The addition of a bidirectional cavopulmonary shunt was proposed if a large, capacious right atrium with poor RV contractility was encountered. ${ }^{11,12}$ The technique of Quaegebeur et $\mathrm{al}^{5}$ was based on similar principles. These pioneering techniques were based on the concept of monocusp coaptation between the abundant anterior valve leaflet and the ventricular septum. The cone reconstruction described by Da Silva et $\mathrm{al}^{6}$ is the first to provide an anatomic repair.

The availability of a cone reconstruction ${ }^{7-9}$ at low operative risk may be an important contribution toward a 


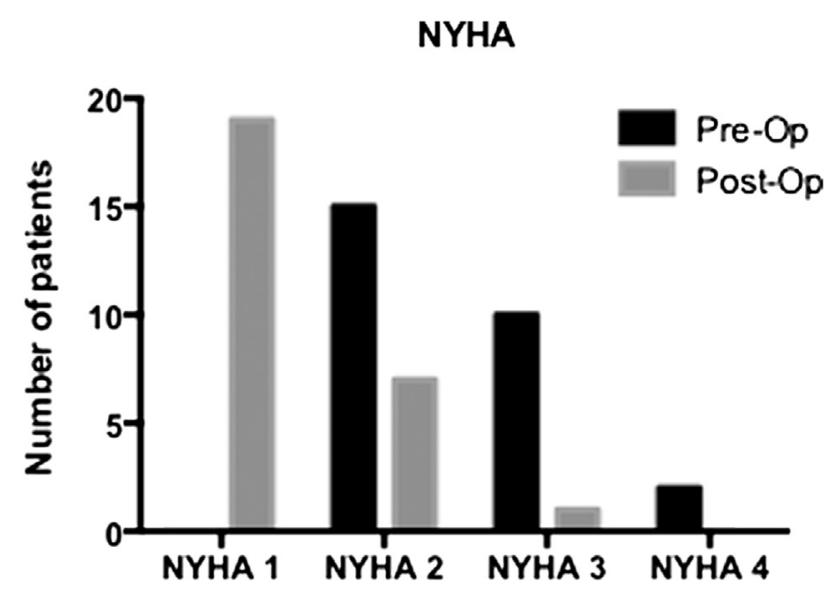

FIGURE 2. Preoperative (preop) and postoperative (postop) New York Heart Association (NYHA) functional class. Cone reconstruction significantly improves functional class as measured by the NYHA grading system.

more robust circulation. Our results are in accordance with other recently published data demonstrating that cone reconstruction effectively reduces TR across a wide range of valve morphology and age ranges. In our experience, small infants can be offered cone reconstruction if the TV is thought to be repairable and the pulmonary vascular resistance is tolerable. On the other hand, surgery for older patients (ie, older than age 60 years) would be considered more risky if the right heart is grossly dilated with poor systolic function, associated with chronic cyanosis.

Regarding the management of the atrialized RV chamber, we adopt a conservative approach, using superficial endocardial sutures to plicate the area of atrialized RV that is relatively devoid of myocardium. These sutures run longitudinally toward the anatomic TV annulus. The importance of a cautious approach to the plication of the atrialized $\mathrm{RV}$ chamber, to avoid distorting the epicardial coronary vessels, cannot be overemphasized. There were no events related to coronary insufficiency in our series.

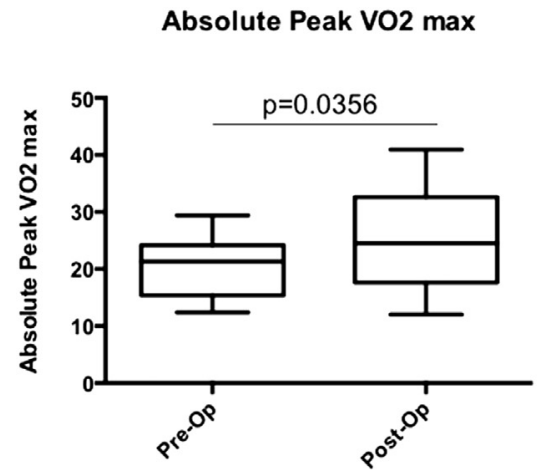

The target dimension of the new TV orifice is a matter of judgment, based on body weight and expected normal dimensions. It is vital to avoid stenosis and at the same time offer optimal support for the new valve. The TV annuloplasty is often downsized to fit a 26 to $32 \mathrm{~mm}$ semirigid annuloplasty ring. This may not be necessary in small children.

The RV outlet must also be free of obstruction, if necessary employing a pulmonary valvotomy.

A major risk when reattaching the cone valve to the new tricuspid annulus is damage to the atrioventricle node resulting in heart block. However this does not appear to be a major issue in our more recent experience. To avoid heart block, we try to suture the septal leaflet 2 to $3 \mathrm{~mm}$ away from the conduction tissue and to remnant valve tissue.

\section{Physiology}

The reconstruction of a cone-shaped valve with $360^{\circ}$ of surrounding native valve tissue appeared intuitively to be a mechanical advantage. Our observations confirmed that the valve competency was maintained.

Anatomic variations in EA involve variable attachment of the anterior leaflet to the septum, variable chordal insertion, displacement and rotation (spiraling) of the effective inflow orifice, and the consequent size of the functional RV. ${ }^{1,13}$ These valvular variations have important consequences on the functional interaction of the right atrium, functional RV, pulmonary circulation, and the LV. Due to ventricular-ventricular interaction, modifications of RV structure will alter LV function. ${ }^{14}$ In addition, some investigators suggest that the LV is also abnormal in EA. ${ }^{15}$ Thus, the outcomes of surgical repair of EA must be considered in terms of both right and left heart performance. ${ }^{16}$

The CMR-derived RV ejection fraction is also a confounded measure of systolic contractility in this group, because of the influence on ejection fraction values by TV

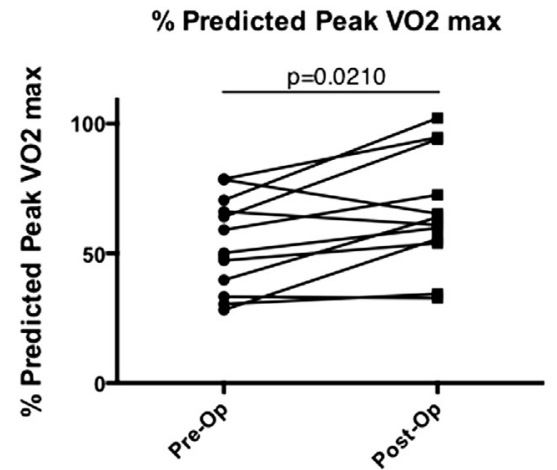

FIGURE 3. Effect of cone reconstruction on objective exercise capacity preoperatively (preop) and postoperatively (postop). The cone reconstruction increased objective exercise capacity in this study, as measured by absolute peak oxygen uptake $\left(\mathrm{VO}_{2}\right.$ max $)$ and the percentage of predicted $\mathrm{VO}_{2}$ max achieved. 
regurgitation and the change in preload related to TV repair. Nevertheless MRI may be a better tool than echocardiography for evaluating RV systolic performance in this group. In this cohort the RV ejection fraction did not change significantly postoperatively. This, combined with elimination of the TR and enhanced forward flow in the pulmonary artery, might represent an improvement in RV myocardial mechanics after repair.

It is not possible to draw firm conclusions about RV function from our data. Serial echocardiographic assessment of the effect of increased RV afterload is currently being undertaken in another study. Anecdotally, several patients in this cohort have shown improved RV systolic function, as measured by echocardiography, at 24 to 36 months postrepair. Whether or not a specific subgroup of patients with EA particularly demonstrates this remodeling will be an important consideration in future studies.

In our current cohort of patients, none had a concomitant Glenn at the time of cone. One patient with major lamination of the TV (involving the anterosuperior as well as mural and septal leaflets) with a small RV infundibular chamber had a Glenn shunt before the cone program. The successful reconfiguration of the very dysplastic EA valve offered a 1-and-a-half ventricle repair. The prospect of growth of the native repaired TV with time may allow removal of the Glenn shunt in due course.

The LV deserves special consideration in these patients. Using CMR, our data showed that the postoperative LV filling was improved significantly. Many patients with EA exhibit abnormal LV function, the etiology of which is not known. Some investigators believe LV dysfunction to be secondary to the abnormal loading conditions resulting from the altered RV. Others consider LV abnormality (eg, myocardial structural change or interstitial abnormality) to be a primary element of EA. In a review of the evidence for LV myocardial dysfunction, it was suggested that noncompaction is frequent in EA and that abnormal muscle bands were occasional findings. ${ }^{1}$ There is a possibility that LV structural abnormalities will manifest clinically more readily following cone reconstruction as a result of higher preload and subtle septal interaction. We did not observe important noncompaction or any deterioration of the LV function in our cohort.

Our finding of better LV filling with well-maintained global function would explain some of the clinical improvements, and may account for the significant improvement in cardiopulmonary exercise that we measured. More detailed LV myocardial characterization at follow-up will offer an opportunity to further investigate the theories of LV myocardial involvement. Some patients did not show a response to surgery based on CMR and cardiopulmonary exercise data. This could possibly be related to decreased ventricular function and timing of surgery. The reasons may become clearer as longitudinal follow-up is extended and they are compared with patients who did not undergo an operation. This work is ongoing.

\section{Study Limitations}

Ours was a retrospective study with a short follow-up and a relatively small sample population, which may have underpowered some of our investigations. This may account for the failure to detect a statistically significant difference in arterial oxygen saturations. However, our detailed analysis was matched using pre- and postoperative data from the same patients, allowing individual comparison over a wide range of patient ages and across a range of clinical severity.

Almost all readily applicable measures of RV systolic function (including MRI ejection fraction) are loaddependent, and are confounded by massive changes in preload and afterload resulting from the cone reconstruction. They also fail to incorporate the complex RV geometry, may be influenced by pericardial constraints, and do not define the atrialized RV chamber dimensions. Moreover, the extremely thin-walled RV does not lend itself to more sophisticated tissue tracking techniques.

\section{CONCLUSIONS}

Cone reconstruction of TV offers an effective repair in patients with EA and severe regurgitation. The patients' clinical status was improved with better LV filling and objective exercise capacity. The durability of repair and mechanisms by which the repair influences biventricular function need longer-term study. It is only with ongoing prospective investigation that the indications for surgery will be better defined, the suitability for patients with different valve morphologies be clarified, and the physiologic complexities of this surgery will be better delineated.

The authors thank Dr Veronica Lisignoli for her work on the early data collection for this study. The authors also thank the cardiologists responsible for the clinical care of the patients in our cohort, including Dr Fiona Walker, Dr Shay Cullen, Dr Bejal Pandya, Dr Graham Derrick, Dr Robert Yates, Dr Ian Sullivan, and Dr Sachin Khambadkone.

\section{References}

1. Attenhofer Jost CH, Connolly HM, Edwards WD, Hayes D, Warnes CA,
Danielson GK. Ebstein's anomaly - review of a multifaceted congenital cardiac
condition. Swiss Med Wkly. 2005;135:269-81.
2. Celermajer DS, Bull C, Till JA, Cullen S, Vassillikos VP, Sullivan ID, et al.
Ebstein's anomaly: presentation and outcome from fetus to adult. J Am Coll
Cardiol. 1994;23:170-6.
3. Danielson GK, Fuster V. Surgical repair of Ebstein's anomaly. Ann Surg. 1982;
196:499-504.
4. Carpentier A, Chauvaud S, Mace L, Relland J, Mihaileanu S, Marino JP, et al.
A new reconstructive operation for Ebstein's anomaly of the tricuspid valve.
J Thorac Cardiovasc Surg. 1988;96:92-101. 
5. Quaegebeur JM, Sreeram N, Fraser AG, Bogers AJ, Stumper OF, Hess J, et al. Surgery for Ebstein's anomaly: the clinical and echocardiographic evaluation of a new technique. J Am Coll Cardiol. 1991;17:722-8.

6. da Silva JP, Baumgratz JF, da Fonseca L, Franchi SM, Lopes LM, Tavares GM, et al. The cone reconstruction of the tricuspid valve in Ebstein's anomaly. The operation: early and midterm results. J Thorac Cardiovasc Surg. 2007;133: 215-23.

7. Anderson HN, Dearani JA, Said SM, Norris MD, Pundi KN, Miller AR, et al. Cone reconstruction in children with Ebstein anomaly: The Mayo Clinic experience. Congenit Heart Dis. 2014;9:266-71.

8. Dearani JA, Said SM, O'Leary PW, Burkhart HM, Barnes RD, Cetta F. Anatomic repair of Ebstein's malformation: lessons learned with cone reconstruction. Ann Thorac Surg. 2013;95:220-6; discussion 6-8.

9. Vogel M, Marx GR, Tworetzky W, Cecchin F, Graham D, Mayer JE, et al. Ebstein's malformation of the tricuspid valve: short-term outcomes of the "cone procedure" versus conventional surgery. Congenit Heart Dis. 2012;7: $50-8$.
10. Coats L, Khambadkone S, Derrick G, Sridharan S, Schievano S, Mist B, et al. Physiological and clinical consequences of relief of right ventricular outflow tract obstruction late after repair of congenital heart defects. Circulation. 2006;113:2037-44.

11. Chauvaud S, Berrebi A, d'Attellis N, Mousseaux E, Hernigou A, Carpentier A. Ebstein's anomaly: repair based on functional analysis. Eur J Cardiothorac Surg. 2003;23:525-31.

12. Chauvaud S. Ebstein's malformation. surgical treatment and results. Thorac Cardiovasc Surg. 2000;48:220-3.

13. Martinez RM, O'Leary PW, Anderson RH. Anatomy and echocardiography of the normal and abnormal tricuspid valve. Cardiol Young. 2006;16(Suppl 3):4-11. 14. Yacoub MH. Two hearts that beat as one. Circulation. 1995;92:156-7.

15. Daliento L, Angelini A, Ho SY, Frescura C, Turrini P, Baratella MC, et al. Angiographic and morphologic features of the left ventricle in Ebstein's malformation. Am J Cardiol. 1997;80:1051-9.

16. Brown ML, Dearani JA, Danielson GK, Cetta F, Connolly HM, Warnes CA, et al. Effect of operation for Ebstein anomaly on left ventricular function. Am J Cardiol. 2008;102:1724-7.

\title{
EDITORIAL COMMENTARY
}

\section{Cone the valve be repaired?}

\author{
Joseph A. Dearani, MD
}

See related article on pages 1144-50.

There have been more techniques of tricuspid repair described for Ebstein malformation than for any other valve abnormality. This is largely due to the apparently infinite anatomic variability present with this anomaly. The cone operation represents an important addition to the surgeon's armamentarium. Although there are basic principles for performing the cone repair, each reconstruction is slightly different depending on the anatomy of the valve and the subvalvular apparatus. The cone reconstruction is the most anatomically natural of all repairs described and can be applied across a wide range of valve morphology and ages. Early results of the cone reconstruction and operative technique have been reported previously by many investigators. In this issue of the Journal, Ibrahim and colleagues report their early results with a small series of patients $(\mathrm{n}=27)$, with attention to postoperative outcome,

From the Division of Cardiovascular Surgery, Department of Surgery, Mayo Clinic, Rochester, Minn.

Disclosures: Author has nothing to disclose with regard to commercial support.

Received for publication Jan 10, 2015; accepted for publication Jan 12, 2015; available ahead of print Feb 19, 2015.

Address for reprints: Joseph A. Dearani, MD, Division of Cardiovascular Surgery, Mayo Clinic, 200 First St SW, Rochester, MN 55905 (E-mail: jdearani@ mayo.edu).

J Thorac Cardiovasc Surg 2015;149:1150-1

$0022-5223 / \$ 36.00$

Copyright (c) 2015 by The American Association for Thoracic Surgery

http://dx.doi.org/10.1016/j.jtcvs.2015.01.016 biventricular function, and exercise capacity. ${ }^{1}$ Their results of reduction in tricuspid regurgitation grade and improvement in New York Heart Association functional class are similar to other reports in the literature. Two issues that Ibrahim and colleagues attempted to address in their current report that are lacking in the literature include detailed postoperative analysis of right ventricular (RV) size, RV function, and exercise capacity.

In the series of Ibrahim and colleagues, ${ }^{1}$ all patients underwent a biventricular repair with atrial septal fenestration. Echocardiographic and magnetic resonance (MR) imaging demonstrated normal left ventricular function before and after the operation. MR imaging showed increased forward pulmonary blood flow and increased left ventricular filling that was probably due to tricuspid competence and not necessarily unique to the cone procedure per se. Interestingly, there were no postoperative reductions in RV end-diastolic and end-systolic dimensions. A reduction in RV size after tricuspid surgery for Ebstein anomaly has not been documented in the literature. Although we have seen the RV get smaller in some patients with Ebstein anomaly after tricuspid surgery, this has been unpredictable. This may be because of insufficient or inaccurate RV dimensions recorded by MR examinations before and after the operation, selective plication of the atrialized $\mathrm{RV}$, the presence of a bidirectional cavopulmonary shunt, and a variable RV remodeling effect. In addition, MR imaging in this review demonstrated no evidence of postoperative improvement in RV function. Similarly, 